\title{
PERANCANGAN HOTEL BINTANG TIGA DENGAN KONSEP HOSPITALITY DI JAKARTA SELATAN
}

\author{
Yogo Suwarno, Rita Laksmitasari, Karya Widyawati \\ Program Studi Arsitektur Fakultas Teknik, Matematika dan Ilmu Pengetahuan Alam \\ Universitas Indraprasta PGRI \\ suwarnoyogo411@gmail.com
}

\begin{abstract}
Abstrak
Tujuan penelitian adalah Membuat sarana tempat tinggal sementara yang dapat menampung kebutuhan pengunjung dengan sarana penunjang yang tersedia, termasuk faktor untuk melancarkan bisnis, kenyamanan, keamanan dan ketenangan yang dapat dipenuhi. Metode perancangan dalam skripsi ini adalah berupa penjelasan dari Proses merancang, yang disertai dengan data-data yang di dapat dari studi literatur mau pun studi lapangan, sehingga dari proses tersebut dapat memberikan suatu gambaran yang sifat nya mendukung objek pada rancangan. Kerangka kajian yang digunakan dalam proses perancangan hotel bintang tiga dikawasan Tanjung Barat ini secara umum, diuraikan dalam beberapa. Setelah penulis menganalisa. Akhirnya penulis dapat menarik kesimpulan bahwa tema dari Hotel Bintang Tiga adalah. "The Spirit of Hospitality" diambil dalam perancangan hotel ini. Spirit mempunyai pengertian semangat dan Hospitality mempunyai pengertian Keramah Tamahan dan ramah lingkungan.
\end{abstract}

Kata Kunci : Jakarta, hotel, hospitality

\begin{abstract}
The purpose of the research is to create temporary accommodation facilities that can accommodate the needs of visitors with available supporting facilities, including factors to smooth business, comfort, security and tranquility that can be fulfilled. The design method in this thesis is an explanation of the designing process, which is accompanied by the data that can be from the study of literature and field studies, so that the process can provide a picture of its nature supporting the object on the design. The review framework used in the design process of three star hotels in the West Cape is generally described in several. After the author analyzes. Finally the authors can draw the conclusion that the theme of the Three Star Hotel is. "The Spirit of Hospitality" is taken in the design of this hotel. Spirit has sense of spirit and Hospitality has understanding Hospitality and environment friendly.
\end{abstract}

Keywords: Jakarta, hotel, hospitality 


\section{PENDAHULUAN}

\section{Latar Belakang}

Sebagai bagian dari ibu kota Republik Indonesia, Jakarta Selatan menjadi salah satu tempat tujuan utama wisatawan baik domestik maupunmancanegara.

Untuk menunjang tingginya tingkat kunjungan keJakarta Selatan, diperlukan ketersediaan sarana akomodasi yang memadai. Sarana akomodasi tersebut antara lain hotel dan restoran. Pada tahun 2014 di Jakarta Selatan terdapat 35 hotel berbintang dengan 7.289 kamar. Sedangkan hotel melati ada 13 hotel dengan jumlah kamar sebanyak 528. Tingkat hunian kamar (TPK) hotel bintang di Jakarta Selatan sebanyak 46.55 persen pada tahun 2014, sedangkan pada hotel melati sebanyak 58,28 persen. Tingkat pemakaian tempat tidur (TPT) pada tahun 2014 untuk hotel bintang sebanyak 42,41 persen, jauh lebih rendah jika dibandingkan dengan TPT pada hotel melati yang mencapai 93,13 persen.Rata- rata lama menginap pada hotel berbintang lebih besar dibandingkan hotel melati, yaitu 2,28 hari pada hotel bintang dan 1,79 hari pada hotel melati. Sementara itu persentase tamu asing pada hotel bintang sebanyak 31,94 persen dan tamu domestik sebanyak 68,06 persen. Persentase tamu asing pada hotel melati sebanyak 10,33 persen dan tamu domestik sebanyak 89,34 persen

\section{TINJAUAN PUSTAKA}

\section{Pengertian Hotel}

Menurut Kamus Besar Bahasa Indonesia kata hotel adalah "bangunan berkamar banyak yang disewakan sebagai tempat untuk menginap dan tempat makan orang yang sedang dalam perjalanan; bentuk akomodasi yang dikelola secara komersial, disediakan bagi setiap orang untuk memperoleh pelayanan, penginapan, makan dan minum"

Pengertian hotel menurut SK Menparpostel Nomoo. KM 34/ HK 103/MPPT 1987 "Hotel adalah bentuk akomodasi yang mempergunakan sebagian atau seluruh bangunan untuk menyediakan jasa pelayanan, pelayanan penginapan, makanan dan minum, serta jasa lainnya untuk umum, yang kelolah secara komersial serta memenuhi persyaratan yang ditetapkan dalam kepusan pemerintah"

Sedangkan pengertian hotel meurut Lawson, 1976 Hotel adalah "Sarana tempat tinggal umum untuk wisatawan dengan memberikan pelayanan jasa kamar, penyedia makanan dan minuman serta akomodasi dengan syarat pembayaran"

\section{Pengertian Hospitality}

Dari aspek fisik berupa Hospitality Facilities (HF) adalah: segala fasilitas yang berhubungan dengan fasilitas (sarana dan prasarana) pelayanan wisatawan/ tamu/ tourist. penginapan yang bertanggung jawab terhadap lingkungan yang mengikuti praktek hidup hijau (green living). konsep yang mengutamakan pelestarian dan perbaikan lingkungan adanya hubungan timbal balik antar makhluk hidup di dalamnya. mengurangi dampak besar pada kerusakan lingkungan, ataupun merubah sistem penggunaan energi (sumber daya) dan sistem pembuangan.

\section{METODE PERANCANGAN}

\section{Proses pengumpulan data \\ Data Primer \\ Merupakan data yang diperoleh melalui proses pengambilan data secara}


langsung pada lokasi, dengan cara sebagai berikut:

1. Metode observasi yaitu :

metode pengumpulan data dengan cara mengadakan pengamatan dan pencatatan sistematis mengenai hal-hal penting terhadap obyek serta pengamatan terhadap masalah-masalah yang ada secara langsung. Dengan adanya survei lapangan didapat data-data yang sistematis melalui kontak langsung dengan masyarakat yang ada di sekitar tapak, yaitu dengan melakukan indentifikasi karakterkarakter masyarakat guna mengetahui kedudukannya Universitas Sumatera Utara 32 terhadap bangunan. Pelaksanaan survei ini dilaksanakn secara langsung. Survei ini berfungsi untuk mendapatkan data berupa:

a. Ukuran tapak

b. Kondisi kontur tapak

c. Kondisi vegetasi dilokasi tapak

d. Batas batas yang mengelilingi tapak

e. Kondisi Transportasi dan lebar jalan

f. Suasana Tapak yang meliputi Iklim, angina topografi tanah

g. Serta data data pendukung lainnya

2. Metode Dokumentasi

Metode dokumentasi yaitu metode pengumpulan data dengan cara mengambil gambar dari obyek yang diteliti. Pengambilan gambar obyek dilakukan dengan menggunakan kamera atau dengan sketsa gambar. Metode ini dilakukan untuk memperkuat metode sebelumnya, yaitu metode observasi, agar lebih memperjelas data-data yang akan digunakan dalam analisis.

3. Tinjauan proyek sejenis

Tinjauan proyek sejenis ini dilakukan untuk mendapatkan data dari bangunan yang sama baik secara obyek maupun tema.

\section{Data Sekunder}

Yaitu data atau informasi yang berkaitan langsung dengan obyek perancangan tapi sangat mendukung program perancangan, meliputi:

1. Studi pustaka/studi literatur

Metode pustaka yaitu metode pengumpulan data dengan menggunakan atau mengambil dari buku-buku dan internet sebagai sumber bacaan dan referensi yang berkaitan dengan permasalahan yang dibahas. Data yang diperoleh dari studi pustaka ini, baik dari teori, pendapat ahli, serta peraturan dan kebijakan pemerintah menjadi dasar perencanaan sehingga dapat memperdalam analisa. Data yang diperoleh dari penelusuran literatur bersumber dari data internet, buku, majalah, brosur/pamflet, film dokumenter, dan aturan kebijakan pemerintah. Data ini meliputi:

a. RDRTK yang berisi kondisi umum, rencana strategi pada kawasan yang berpotendi dan peta kawasan Jakarta Selatan data.

b. Studi pustaka yaitu metode pengumpulan data dengan melakukan studi literature terhadap buku-buku yang relevan. Studi pustaka meliputi

Data literatur tentang kawasan dan tapak terpilih berupa peta wilayah, dan potensi alam dan buatan yang ada di kawasan. Data selanjutnya digunakan untuk menganalisa kawasan tapak

Lieratur teori teori arsitektur yang relevan dengan tema perancangan dan obyek

Studi Komperatif

Studi komperatif ini adalah studi mengenai pola ruang, bentuk, tata atur, 
dan unsur unsur yang berkaitan dengan objek :

\section{PEMBAHASAN DAN HASIL RANCANGAN}

\section{Tinjauan Tapak}

Lokasi memegang peranan penting dalam menentukan keberhasilan suatu Hotel, terutama dalam memenuhi kegiatan - kegitan penguhuninya.Lokasi Hotel berada tepat di jalan Tanjung Barat Raya, perencanaan Hotel cukup menguntungkan bila di tinjau dari kedudukan tapak terhadap kota Jakarta.

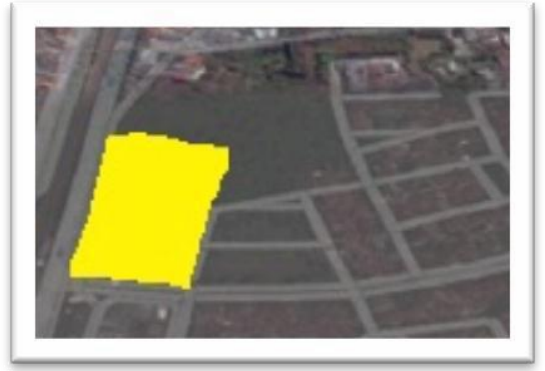

Gambar 1. Lokasi dan Layout tapak

\section{Konfigurasi Tapak}

Pola perletakkan/orientasi masa serta sirkulasi akan diletakkan menghadap ke arah Barat karea mempertimbangkan masalah kenyamanan dalam bangunan dan Memanfaatkan Pencahayaan Alami di waktu siang hari

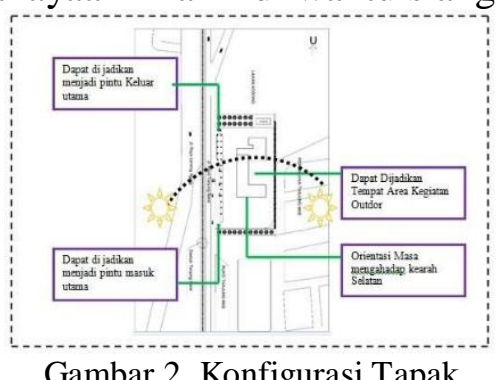

\section{Penzoningan}

Pembagian ruang dalam Hotel bintang tiga di tanjung barat ini terbagi dalam tiga kelompok / area besar yaitu :

1. Area publik

yang terdiri atas zona parkir dan zona penerima.
2. Area pelengkap

yang terdiri dari zona semi publik dan semi privat. Zona semi privat dan semi publik terdiri atas ruang pengelola, ruang servis (housekeeping, food \& baverage, furniture storage, MEE, dll) dan ruang rental untuk travel agent, money changer, minimarket.

3. Zona privat

Yang merupakan zona utama berupa kamar hotel.

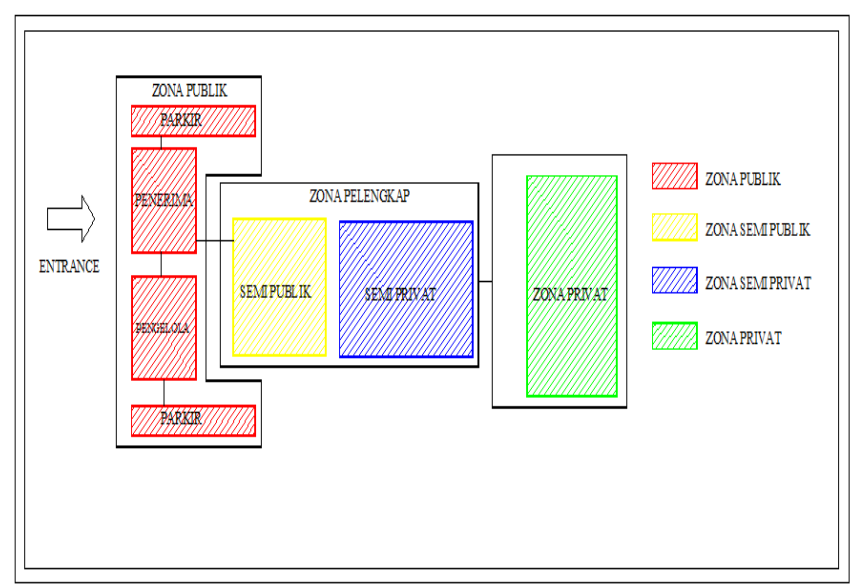

Gambar 3. Penzoningan

\section{Tranformasi Bentuk}

Bentuk bangunan diciptakan dari hasil transformasi kata kunci bangunan, Ramahlingkungan "dengan alam dan, terbuka" kepada sesama. Bentuk yang mengesankan ,bersahabatte dengan alam :

1. Bujur persegi panjang diterapkan dalam setiap komposisi dasar bentuk ruang, terdapat 3(tiga) variasi wujud berupa wujud dasar,penambahan dan pengurangan. Penerapan ditujukan pada ruangyang memiliki keterdekatan hubungan dan fungsi.

2. Bentuk persegi panjang yang digabung menjadi satu sehingga banguanan beberbentuk seperti $U$ untuk di lantai dasar dan untuk lantai 1 sehingga 5 berbentuk L dimana 


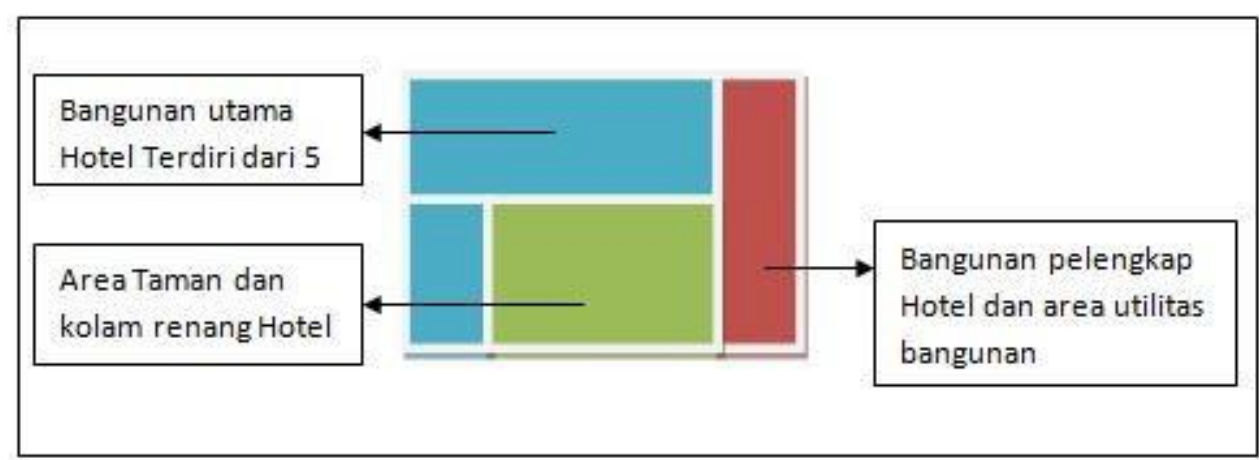

Gambar 4. Tranformasi Bentuk

Massa fasilitas utama diambil dari bentuk tipologi geometri Hotel yang dominan mengikuti grid, yang pada umumnya berbentuk persegibersifat manusiawi dan memberikan kemudahan sirkulasi kepada para pengunjung, bentuk massa yaitu berbentuk Tipe bangunan L sangat cocok dengan tipologi geometri Hotel.memanfaatkan sisa dari bangunan bentuk $\mathrm{L}$ tersebut untuk digunakan sebagai kolam atau taman kecil sehingga bisa terlihat lebih sejuk dan juga lebih nyaman.

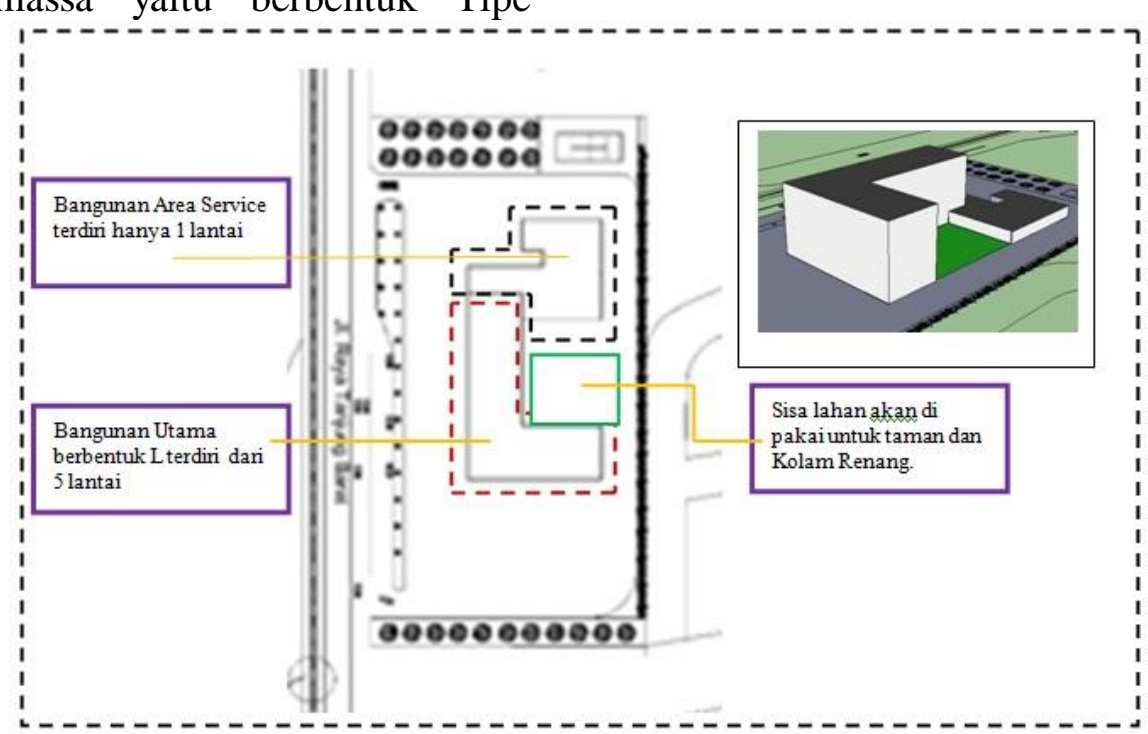

Gambar 5. Tipologi geometri hotel

\section{Konsep Material}

Material dan tekstur yang berkesan „bersahabate dengan alam di ciptakan dengan penggunaan material - material yang berasal dari buatan manusia. Material buatan manusia diciptakan dengan tekstur yang halus (akan memberi kesan yang tidak egois). Material dan tekstur yang berkesan ,terbuka ${ }^{\text {ee }}$ diciptakan dengan penggunaan material kaca dan dengan penggunaan material yang bertekstur halus.

1. Dinding

Penggunaan dinding batahebel yang dilapisiplester acian dan bukaan dengan material kaca merupakan pilihan material yang sesuai dengan lingkungan sekitar dan ketersediaan material tersebut. 

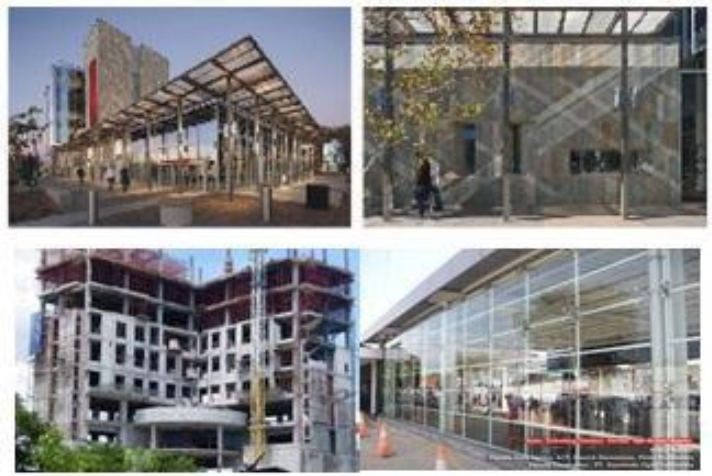

Gambar 6. Konsep material dindingDesain

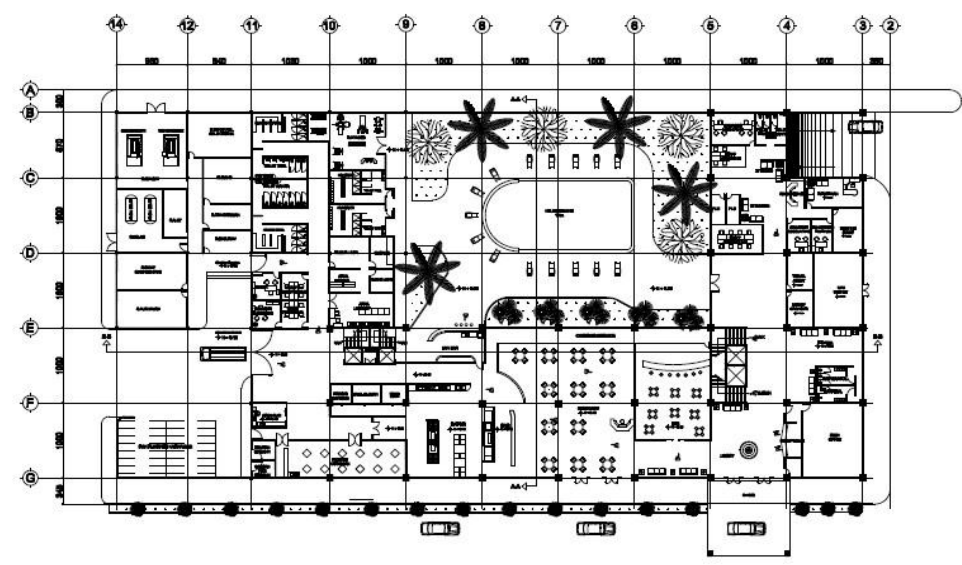

Gambar 7. Denah Lantai Dasar

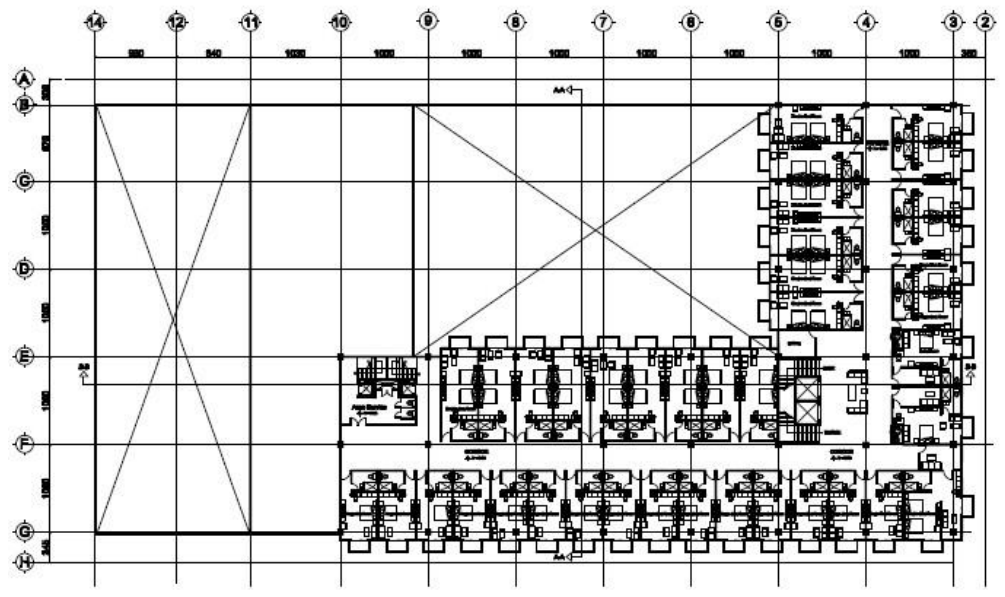

Gambar 8. Denah Lantai 2 - Lantai 4 Tipical 


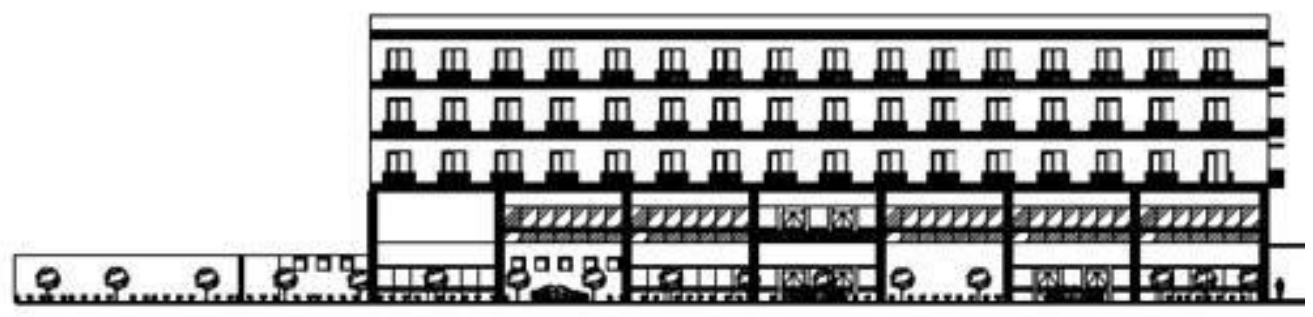

Gambar 9. Tampak depan
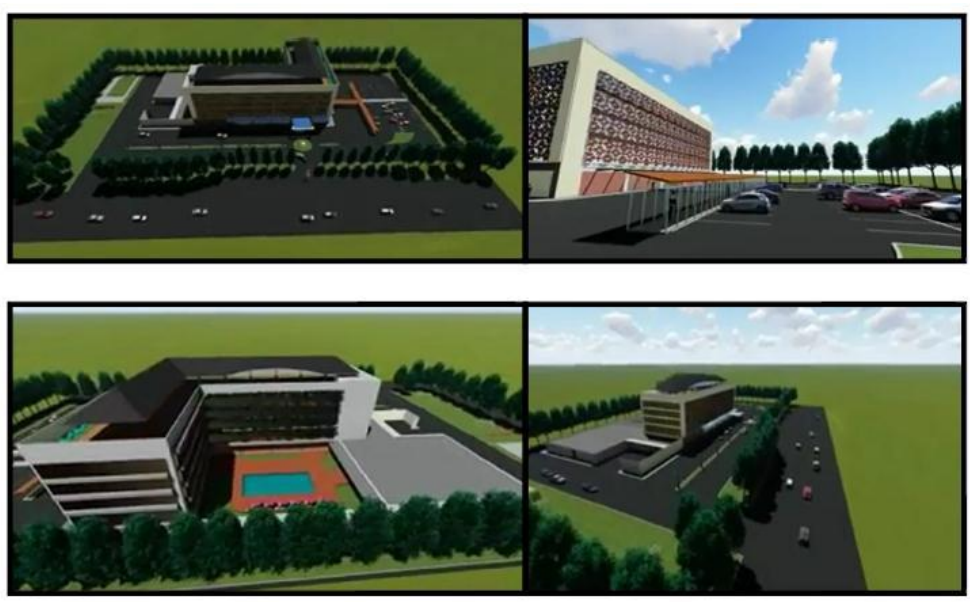

Gambar 10. Perspektif exterior
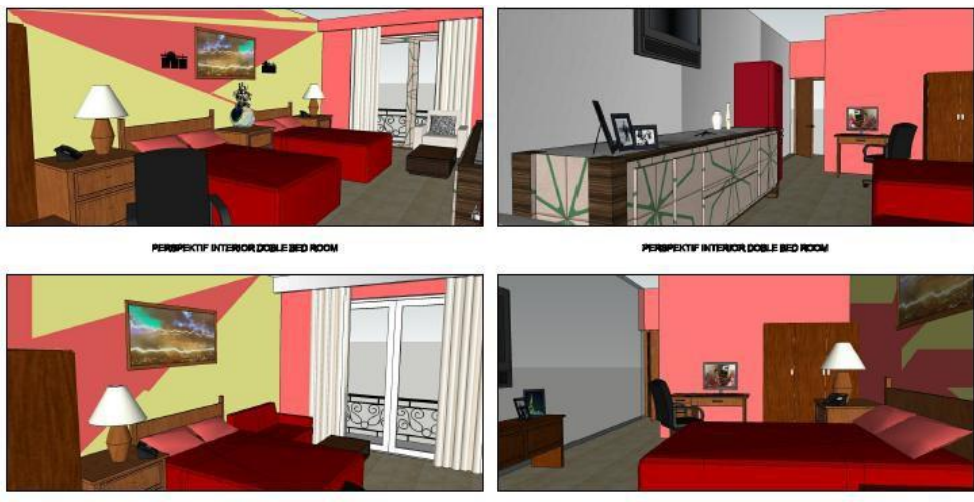

Gambar 11. Perspektif Interior

\section{SIMPULAN}

Sebagai hotel bisnis yang memiliki standar nasional dan telah berkembang di beberapa daerah di seluruh Indonesia, Hotel Tanjung Barat memiliki peranan penting dalam memajukan perekonomian masyarakat Jakarta Selatan melalui keberadaan hotel, serta dapat memasarkan dan memenuhi kebutuhan hotel berbintang di kotaini. Hotel
Tanjung Barat mempunyai visi "Business, vacation with family".Selain nyaman bagi pengunjung, desain interior yang baik juga menciptakan suasana yang rileks selaras dengan keinginan klien beserta standar tema yang diterapkan. Dengan pencapaianpencapaian tersebut sangat diharapkan hotel baru ini dapat berkembang seiring dengan berkembang nya kota Jakarta. 


\section{DAFTAR PUSTAKA}

Panero, J. (1979). Dimensi manusia dan Ruang Interior. Jakarta. Luthfie,

M. (2008). Tugas Akhir. Bandung

Marlina,E. (2008). Panduan Perancangan Bangunan Komersial. Andi.Yogyakarta.

Neufert, E. (2000). Data ArsitekJilid 2, Jakarta: Erlangga

Juwana, J.S. (2005). Panduan Sistem Bangunan Tinggi. Erlangga.
Jakarta Prinsip City Hotel, Menurut Surat Keputusan Menteri Perhubungan R.I No. PM 10/PW - 301/Phb. 77, tanggal 12 Desember1977, Studi Kasus: Putri Duyung, Ancol, Jakarta Utara 46

http://soddis.blogspot.co.id/2014/03/pen gertian-definisi-hotel-bisnis.html http://ejournal.uajy.ac.id/1217/6/5TA12 684.pdf 